INTERVIEW

For reprint orders, please contact: reprints@futuremedicine.com

\section{Tamoxifen, raloxifene and selective estrogen receptor modulators to estrogen-induced apoptosis, one thing led to another}

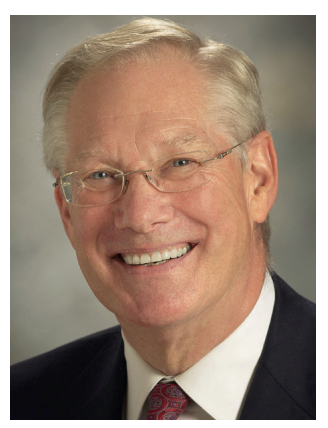

V Craig Jordan* speaks to Roshaine Gunawardana, Commissioning Editor: V Craig Jordan, OBE, PhD, DSc, MDhc, FMedSci is the Dallas/Ft Worth Living Legend Chair of Cancer Research, Professor of Breast Medical Oncology, Professor of Molecular and Cellular Oncology, Chief, Section of Basic Science Research and Pharmacology, Department of Breast Medical Oncology University of Texas MD Anderson Cancer Center (TX). He trained as a pharmacologist at Leeds University Medical School and subsequently held Professorial appointments at the University of Wisconsin (WI), Northwestern University (IL) (Diana, Princess of Wales Professor of Cancer Research), the Fox Chase Cancer Center (PA), (the Alfred G. Knudson Chair of Cancer Research) and previously the Professor of Oncology and Pharmacology at Georgetown University Medical Center and the Scientific Director of the Georgetown Lombardi Comprehensive Cancer Center, Washington, D.C. He developed the scientific principles for the effective use of tamoxifen, as an adjuvant therapy for breast cancer and the use of tamoxifen, as the first chemopreventive for any cancer. His discovery and translational research of the novel group of medicines, known as Selective Estrogen Receptor Modulators, resulted in the development of raloxifene, for the prevention of osteoporosis and breast cancer. His contributions to medicine have been recognized with more than four dozen International Awards, including the Inaugural Brinker International Award (Susan G. Komen for the Cure), David A. Karnofsky Award (ASCO), the American Cancer Society (ACS) Medal of Honor, ACS Chemoprevention Prize (ASCO), the Charles F. Kettering Prize and the St. Gallen International Breast Cancer Prize. He is a Member of the National Academy of Sciences, a Fellow of the Academy of Medical Sciences and an Honorary Fellow of the Royal Society of Medicine. In 2002, he was appointed Officer of the Most Excellent Order of the British Empire, for services to International breast cancer research.

\section{Q Your translational research contributions to breast cancer research and management have continued for four decades. What is the secret of this success story?}

The teams I created at six different institutions around the world all had bright intelligent young medical scientists, with a back bone of experienced scientists who had published in the area. Each institution brings new opportunities with advances in breast cancer research and treatment. The formula is straightforward: devise models to describe mechanisms that create medicines. We covered the whole spectrum of therapeutic research with nonsteroidal antiestrogens with the goal of treating human disease. It is the conversation between the laboratory and the clinic that is the secret of our success.

*Department of Breast Medical Oncology, University of Texas, MD Anderson Cancer Center, Houston, TX 77030, USA; VCJordan@mdanderson.org

\section{Breast Cancer Management}

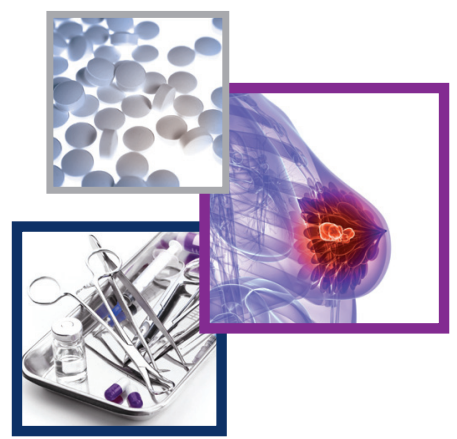

\section{KEYWORDS}

- estrogen induced apoptosis

- hormone replacement therapy

- raloxifene - selective estrogen receptor modulators • tamoxifen 
Q You call your research groups your 'tamoxifen teams'. What is your driving philosophy?

The tamoxifen teams each rely on their coworkers to succeed. Models are passed down from generation to generation in my teams. I have one goal to reinvest in the future education and provide opportunities for new generations of medical scientists. These young scientists take my ideas and convert those ideas into lives saved. I have often said that I am like Major J Reisman played by Lee Marvin in the film 'The Dirty Dozen'. These are my teams that I train to be world class.

Q What advice would you give to a young medical scientist starting their career in breast cancer research?

I call these my scientific survival suggestions:

- Carefully decide on your mentor/supervisor for your doctorate;

- Train yourself to ascend in science;

- Get documentation that says what you can do;

- Experiments are a conversation with nature;

- Follow your instincts on what you want to achieve; have a goal;

- Know an opportunity when you are presented with change;

- Give chances to allow your team members to excel;

- Understand it is your responsibility to obtain support for your science;

- Science can be distracting but publish or perish;

- When you publish, your colleagues and competitors will often ignore your landmark work!

These suggestions have been published in my book 'Estrogen Action, Selective Estrogen Receptor Modulators and Women's Health. Progress and Promise'. They were distilled based upon experiences in my own career.

Q You have just moved to The University of Texas MD Anderson Cancer Center where you have been honored with the Dallas/Ft Worth Living Legend Chair of Cancer Research as Professor of Breast Medical Oncology, but how does anyone become the Diana, Princess of Wales Professor of Cancer Research as you were between 1999 and 2004?

In 1995, when I was the Director of the Breast Cancer Research programme at the Robert $\mathrm{H}$ Lurie Comprehensive Cancer Center of Northwestern University Medical School, Chicago, the Cancer Center Director, S Rosen, was approached by People magazine to organize a three-day fund-raising event in 1996. Steve invited me to organize a symposium on breast cancer and Diana, the Princess of Wales agreed to be my keynote speaker. Speakers included: B Weber, MD, of the University of Pennsylvania, L Van Horn, PhD and M Morrow, MD, of Northwestern University, K Antman, MD, of Columbia University, N Brinker of the Susan G. Komen Breast Cancer Foundation, B Healy, MD, of The Ohio State University and former NIH Director and myself. Following her visit Diana and I continued to correspond and there were plans for her to return with her two sons, William and Harry; but this was not to be. Her untimely death on August 31, 1997 in Paris, shocked the world. A month later our Cancer Center received a sizable anonymous donation to create a Chair known as the Diana, Princess of Wales Professor of Cancer Research. Her sister Lady S McCorquodale sent a letter stating: "I speak for all members of the Princess's family in saying that there is no objection to the naming of the professorship in her memory." Following my induction as the Diana, Princess of Wales Professor of Cancer Research on October the 23rd, 1999, the Earl Spencer, her brother, wrote to me saying: "I am sure she would have been more than delighted at your success with the development of tamoxifen, and to have been linked with your achievements both past and future."

Q In an earlier commentary (Breast Cancer Management. 3, 321-326 [2014]), you mapped out the changes in cancer medicine that occurred with the clinical use of tamoxifen. But what was the most gratifying translational research event for you?

There is no doubt in my mind that the most immediately important discovery we made was the finding that tamoxifen controls the growth of estrogen-induced breast cancer but stimulates the growth of a human endometrial tumor implanted in the same animals [1]. Tamoxifen could be 
dangerous to women by elevating the risk of endometrial cancer during long-term adjuvant therapy. By coincidence, I was invited to speak at the University of Bologna Medical School, Bologna, Italy on the occasion of their 800th anniversary. I chose to talk about my concerns with tamoxifen. Imagine my surprise when Dr L Hardell wrote to the Lancet echoing my concerns a few months later [2]. What then occurred was a flurry of letters $[3,4]$ and then a paper in the Lancet by Dr T Fornander and co-workers [5] who confirmed our predictions in patients. This was the year following our laboratory publication containing a warning to the clinical community in 1988 [1]. As a result of these findings, gynecologists, for the first time, became involved in breast cancer patient care. Zeneca rapidly responded with label changes for tamoxifen. Undoubtedly lives were saved and all of this process occurred very quickly within 2 years. This was just in time for gynecological monitoring in all future chemoprevention trials with tamoxifen.

\section{Q How did the new group of medicines selective estrogen receptor modulators happen?}

This occurred at the University of Wisconsin Comprehensive Cancer Center (WI, USA) with the discovery that tamoxifen and raloxifene (then a failed and discarded breast cancer drug) would maintain bone density in ovariectomized rats [6] Additionally, tamoxifen and raloxifene had chemopreventive actions on rat mammary cancer [7]. Finally, tamoxifen stimulated the growth of endometrial cancer but raloxifene was not estrogen-like in the rodent uterus. It was clear that the nonsteroidal antiestrogens, as they were then called, were switching on and switching off estrogen target tissues around the body. They were selective estrogen receptor modulators and a new group of medicines was conceived [8] for clinical development in women's health.

Q You are currently focused on the new biology of estrogen-induced apoptosis that you discovered in your laboratory. This seems a counterintuitive action of estrogen when everybody knows that estrogen is the bad player in breast cancer. Can you explain? The rules are now quite clear. Breast cancer, that is estrogen receptor positive, requires more than five years of estrogen deprivation to be able to have surviving cell populations that grow in an estrogen-deprived environment. However, this population is now vulnerable to the cytotoxicity of physiological estrogen. Estrogen is the trigger for apoptosis in these vulnerable cells. These concepts have recently been reviewed [9].

Q In recent years you have been engaged in the debate about the results of the Women's Health Initiative clinical study. Can you briefly state the issues being addressed?

The Women's Health Initiative consist of two trials conducted in women more than 10 years past their menopause. The surprise in the estrogen alone trial versus placebo was the unanticipated sustained decrease in breast cancer incidence. Although this was apparently a surprise to the epidemiology and gynecology community, the science was already established in the refereed literature. These laboratory data confirmed that long-term estrogen deprivation results in cell populations that are killed by physiological estrogen levels. This is a perfect case of translational research that is a conversation between the laboratory and the clinic. In the clinical trial, a question was asked of Nature but Nature cannot lie and the answer therefore has veracity because of the placebo control. The laboratory work explained the mechanism of estrogen-induced apoptosis.

\section{Q If estrogen in the Women's Health}

Initiative trial reduced breast cancer incidence, then why do you think that the combination of estrogen plus a progestin now increased breast cancer incidence?

We discovered that estrogen-induced apoptosis is preceded by a profound inflammatory response [10]. We reasoned that an anti-inflammatory glucocorticoid had the potential to inhibit estrogen-induced apoptosis. We found that dexamethasone completely inhibits estrogen-induced apoptosis. So the question now became why would medroxyprogesterone acetate (MPA) in hormone replacement therapy (HRT) block apoptosis if it was a progestin? But MPA is not a pure synthetic progestin; it is well known that MPA has associated glucocorticoid activity. We recently showed [11] that MPA will blunt estrogen-induced apoptosis and over time new cell populations grow back. These data are consistent with the increased incidence of breast cancer in the HRT study. It is now possible to design a safer HRT with a progestin that has no glucocorticoid activity. These synthetic progestins have already been used for years by women in oral contraceptives. 
Q What are the missing pieces of your current research puzzle?

My invitation to join the staff in Breast Medical Oncology by Dr D Tripathy provides my last tamoxifen team with a fabulous opportunity. Over the past decade, we have used established cell lines to create models of estrogen-deprived cell growth to study the mechanism of estrogeninduced apoptosis. We have documented an important advance in estrogen pharmacology which, as it turns out, is a previously unappreciated cytotoxicity of estrogen, a women's natural sex steroid. We plan to advance this knowledge by creating up to 50 brand new estrogen receptor positive breast cancer cell lines, linked to patient outcomes and to determine whether we can maximize the current $30 \%$ response rate of estrogendeprived tumors to be $100 \%$. This would lead to a cheap and effective way of gaining years of life for women with metastatic breast cancer.

\section{Although you have worked in America since 1980, I believe you maintain strong ties to Britain through your scientific work and through your continuing connections with the British army. What are your continuing academic connections?}

In the UK, I was elected to be a Fellow of the Academy of Medical Sciences in 2009. This is the British equivalent of the National Academy of Medicine in the USA. Additionally, I was elected as an honorary Fellow of the Royal Society of Medicine in 2008 which is their highest honor. Only 100 honorary Fellows are permitted to be selected in total. I am also the elected President of the Royal Society of Medicine Foundation of North America and our goal is to foster close ties between USA, Canada and the UK with medical prizes and opportunities to attend medical meetings in London. Most Importantly, I wish to foster scientific interactions with the University of Leeds (my alma mater) and the MD Anderson Cancer Center and also reinvest in a new generation of British medical scientists. Last year, I presented the 2014 University of Leeds Distinguished Alumni Lecture [12]. I have also supported, for 20 years, the Craig Jordan Prize in Medicinal Chemistry at the University. Recently, I was invited to support the Craig Jordan Translational Research Lecture at the Weatherall Institute of Molecular Medicine at the University of Oxford. These lectures are intended to inspire a new generation of medical scientists.
Q Finally, why the army? It seems an unlikely combination 'the Father of Tamoxifen' and military operations!

I volunteered for Leeds University Officers Training Corps (LUOTC) and I was commissioned as an infantry officer. Very rapidly, I was recruited to become a Captain in the Intelligence Corps on the staff of the Deputy Chief Scientist for the army at the Ministry of Defense. My responsibilities to him were Nuclear, Biological, and Chemical (NBC) warfare in the event of a Russian invasion in Europe. I was a PhD student in Leeds! When I went to America (1972-74), I became the first British officer attached to the NBC defense of the Eastern Sea-board of the USA, I was a postdoc! Then, when I returned to $\mathrm{UK}$ as a lecturer in pharmacology in 1974 I was recruited by the Special Air Service for NBC work in time of war. In 1979, on my return to USA, I became a Regular Army Reserve officer in the Special Air Service until the age of 55, I would be reactivated in time of war. Today, Her Majesty has approved my appointment as the Honorary Colonel of LUOTC and have for the past twenty years, sponsored the Jordan Prize for the best cadet in the Regiment. To answer your question why this combination? It was the opportunities I received to further my science at the University of Leeds that opened the door for me to give back and serve the country for the opportunities I had received, free of charge, during my education. A commitment to the future and country is a principle in which I firmly believe.

\section{Disclaimer}

The opinions expressed in this interview are those of the interviewees and do not necessarily reflect the views of Future Medicine Ltd.

Financial \& competing interests disclosure

This work was supported by Susan G Komen for the Cure Foundation under award number SAC100009, the benefactors for the Dallas/Ft Worth Living Legend Chair of Cancer Research and the National Institutes of Health NIH, MD Anderson's Cancer Center support grant CA 016672. $V C$ Jordan has no other relevant affiliations or financial involvement with any organization or entity with a financial interest in or financial conflict with the subject matter or materials discussed in the manuscript apart from those disclosed.

No writing assistance was utilized in the production of this manuscript. 


\section{References}

1 Gottardis MM, Robinson SP, Satyaswaroop PG, Jordan VC. Contrasting actions of tamoxifen on endometrial and breast tumor growth in the athymic mouse. Cancer Res. 48(4), 812-815 (1988).

2 Hardell L. Tamoxifen as risk factor for carcinoma of corpus uteri. Lancet 2(8610), 563 (1988).

3 Jordan VC. Tamoxifen and endometrial cancer. Lancet ii, 1019 (1988).

4 Jordan VC. Tamoxifen and endometrial cancer. Lancet i, 733-734 (1989).

5 Fornander T, Rutqvist LE, Cedermark B et al. Adjuvant tamoxifen in early breast cancer: occurrence of new primary cancers. Lancet i, 119-124 (1989).
6 Jordan VC, Phelps E, Lindgren JU. Effects of anti-estrogens on bone in castrated and intact female rats. Breast Cancer Res. Treat. 10, 31-35 (1987).

7 Gottardis MM, Jordan VC. Antitumor actions of keoxifene and tamoxifen in the $\mathrm{N}$-nitrosomethylurea-induced rat mammary carcinoma model. Cancer Res. 47, 4020-4024 (1987).

8 Lerner LJ, Jordan VC. Development of antiestrogens and their use in breast cancer: eighth Cain memorial award lecture. Cancer Res. 50, 4177-4189 (1990).

9 Jordan VC. The new biology of estrogeninduced apoptosis applied to treat and prevent breast cancer. Endocr. Relat. Cancer 22(1), R1-R31 (2015).
10 Ariazi EA, Cunliffe HE, Lewis-Wambi JS et al. Estrogen induces apoptosis in estrogen deprivation-resistant breast cancer through stress responses as identified by global gene expression across time. Proc. Natl Acad. Sci. USA 108, 18879-18886 (2011).

11 Sweeney EE, Fan P, Jordan VC. Molecular modulation of estrogen-induced apoptosis by synthetic progestins in hormone replacement therapy: an insight into the women's health initiative study. Cancer Res. 74, 7060-7068 (2014).

12 University of Leeds Distinguished Alumni Lecture. Unlikely action, unexpected consequences - Leeds' role in breast cancer breakthrough - the tamoxifen tale. https://youtu.be/AbvHqCtNCl8 